\title{
Damages to stent stabilized left ventricular pacemaker electrodes during simulated lead extraction
}

\author{
Romola Laczkó, Tibor Balázs, Eszter Bognár \\ BME, Dept. of Materials Science and Engineering. H-1111 Budapest, Bertalan L. u. 7. Hungary \\ János Ginsztler \\ Research Group for Metals Technology of HAS and BME, 1111 Budapest, Goldmann ter 3. Hungary
}

\begin{abstract}
During biventricular pacemaker implantation stents can be applied for coronary sinus lead stabilization to prevent lead dislocations. A lot of issues have been raised in connection with the use of the stent. In some cases the implanted left ventricular lead must be explanted. It is crucial to avoid any injury to the heart when the electrode is removed. Another very important question concerns the type of injuries the electrode may cause during the removal process. An extraction model has been prepared using a special curve and a polymer tube. After the pacemaker leads were extracted, various microscopic examinations were executed. The findings may to make such intervention methods more successful, helping to better stabilize the electrode and to keep injuries during interventions to a minimum.
\end{abstract}

KEYWORDS. Coronary stent; Left ventriculal pacemaker electrode; Simulated lead extraction.

\section{INTRODUCTION}

A pacemaker (PM) is an electronic device implanted in the body to regulate the heart beat. It consists of a battery and electronic circuits enclosed in a hermetically sealed can. The PM delivers electrical stimuli over leads with electrodes in contact with the heart [1]. Fig. 1 shows an X-ray picture of an implanted pacemaker system in a human chest.

Cardiac resynchronization refers to stimulation techniques that change the degree of atrial and ventricular electromechanical asynchrony in patients with major intra-atrial or interatrial and ventricular conduction disorders. More recently for the treatment of heart failure, the left ventricle may be paced by inserting a lead into a tributary of the coronary sinus, a venous structure on the epicardial surface of the left ventricle [1]. Despite major advances of lead and pacemaker techniques, the implantation of a biventricular pacemaker is still a challenging and complex procedure. Introducing the left ventricular pacing lead into the sinus coronaries may cause difficulties. The dislocation rate of coronary sinus (CS) leads used for biventricular stimulation is high. Stent implantation to stabilize the left ventricular lead is a useful and safe procedure in the treatment of CS lead instability. The electrode is positioned into the desired position, and a metal coronary stent is introduced via a guide wire through the coronary sinus. After pacing measurements the stent is deployed at 5 to $30 \mathrm{~mm}$ proximal to the tip of the electrode [2]. Fig. 2 presents the parts of a steroid eluting pacemaker head.

There is a risk of incidents, especially infections when the implanted left ventriculum lead is to be explanted. Therefore, it is crucial to avoid any injury to the heart when the electrodes are removed. During the process of removal the vein wall may be injured. To avoid this, it is to be decided first if the electrode can be explanted as the stent may damage the 
electrode in a way it may break and the tip may be left in the vessel or the coating may be damaged. It is also important to consider the type and size of the stent in order ensure the most appropriate fixation. The aim of our article is to examine the damages the electrode explantation may cause to the electrodes and stents and to find the most convenient stent for electrode fixation.

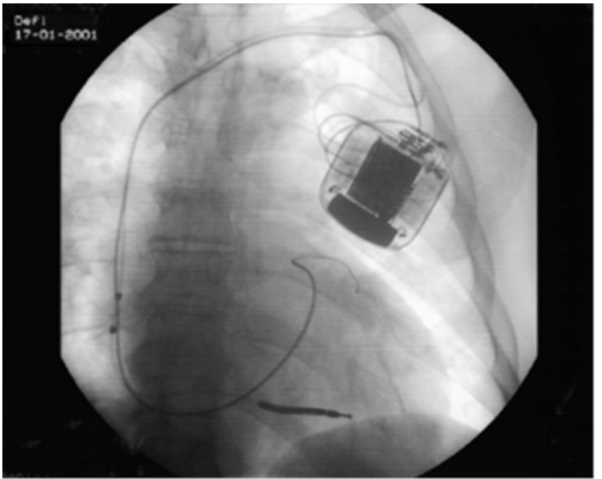

Figure 1: X-ray picture of an implanted pacemaker and electrodes [5].

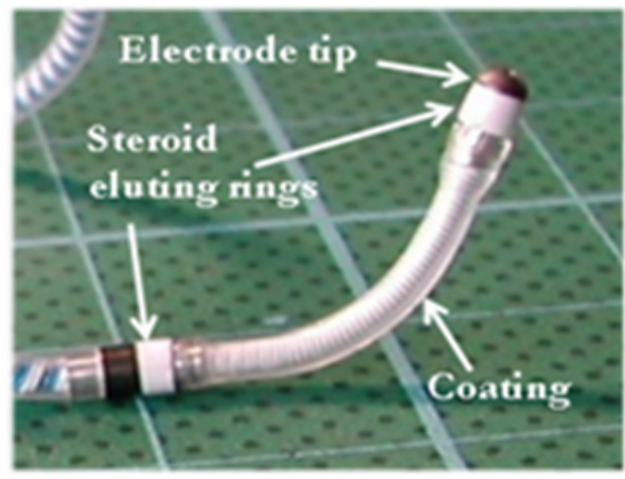

Figure 2: The head of a pacemaker electrode

\section{METHODS}

A special curve was shaped to model the bend of the outer surface of the left ventricle. The curve was formed in a sheet made from foamed polystyrene show in Fig. 3. The sheet was $50 \mathrm{~mm}$ long, $30 \mathrm{~mm}$ wide and $30 \mathrm{~mm}$ thick. The Left Ventricular Diastolic Diameter (LVDD) is typically about $70 \mathrm{~mm}$ and the representative wall thickness of the left ventriculum of patients receiving cardiac resynchronization therapy is 10 to $20 \mathrm{~mm}$ [3]. Accordingly, the radius of the test curve was $90 \mathrm{~mm}$. A silicon tube was inserted into the curve and the electrodes were stabilized with coronary stents in the tube.

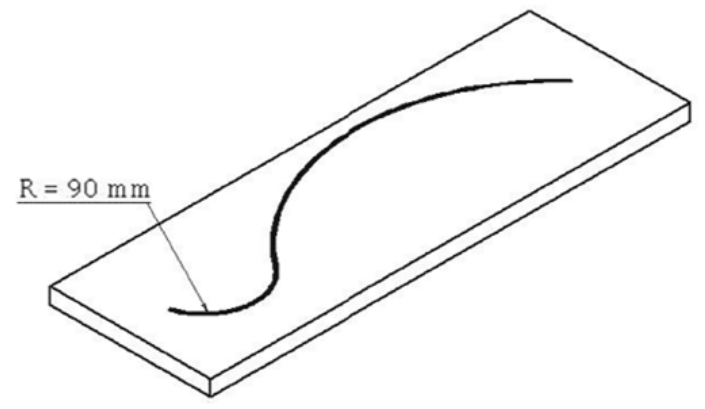

Figure 3: curve to model the bend of the left ventriculum where the lead is implanted.

The first step of the procedure was to fill the tube with physiological saline. Since the electrode is surrounded by blood in the ventricle, similar wet conditions had to be ensured in order to minimize the friction between the stent and the electrode. It was achieved by filling the tube with physiologic solution.

Secondly, the electrode was led up to the end of the tube and coronary stents attached to a balloon were used to fix the electrode. The stents were expanded with an indeflator. The indeflator is a pump complete with a pressure meter and is filled with Ringer's solution. Since maximum pressure is normally used to expand stents in practice, the same pressure $(26$ bar) was chosen in our experiments. Our aim was to achieve the maximum available diameter of stents with this method. After the electrode was fixed with the expanded stent, the guide wire and balloon catheter were removed. Finally the electrode was slowly and carefully extracted. The procedure was monitored with stereomicroscope. The indeflator was filled with a turquoise liquid for better visibility because polymer tube modelling the vein is not completely transparent. This method makes it possible to follow the process of the expansion more precisely: in the picture the silhouette is sharp. 


\section{THE ELECTRODES AND STENTS EXAMINED}

$\mathrm{F}$ ive coronary stents and Corox OTW 75-UP steroid eluting electrodes were examined. The inner diameter of the polymer tube was $5 \mathrm{~mm}$ and the maximum diameter of the electrodes was $1.95 \mathrm{~mm}$. Using this method, the experiments were made only with the minimum $3 \mathrm{~mm}$ - diameter stents. They were examined with a stereo microscope (Nikon SMZ2T), a scanning electron microscope (Philips XL 30) and a metallograph inspection microscope (Olympus PMG-3 with Olympus digital camera).

\section{$4.5 / 13 \mathrm{~mm}$ stent}

During the process shown in Fig.4, the stent did not slip out or split. This way the vein can be protected against perforation. In Picture a), the stent is placed next to the electrode. In Picture b), the stent is expanded with the balloon filled with turquoise liquid. In Picture c), the balloon is removed and the electrode is fixed by the stent. In Picture d), the electrode is extracted and the stent is deformed slightly.

a)

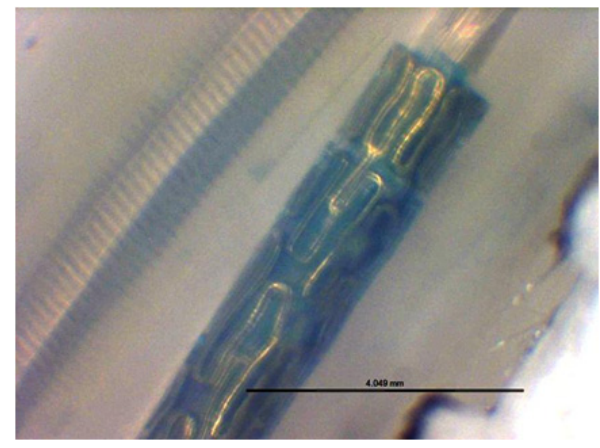

c)

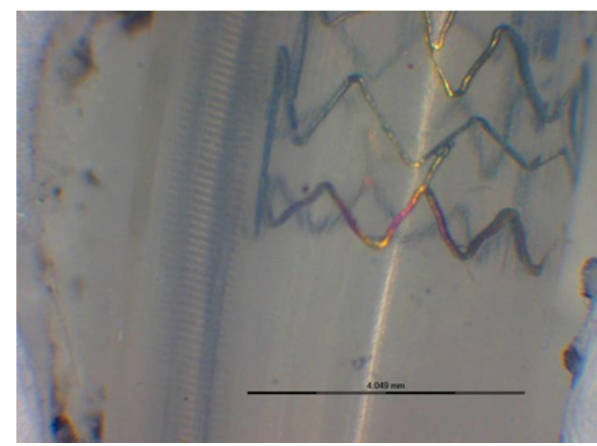

b)

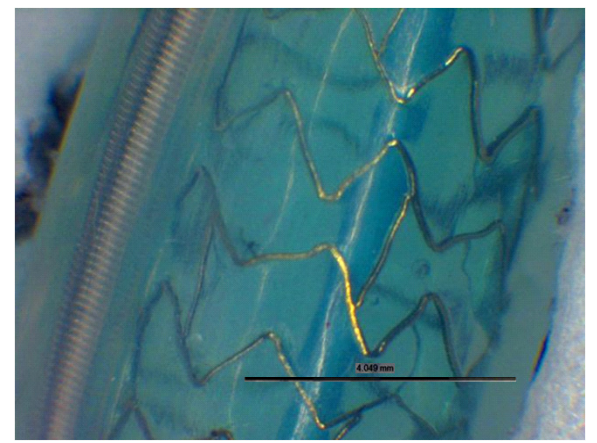

d)

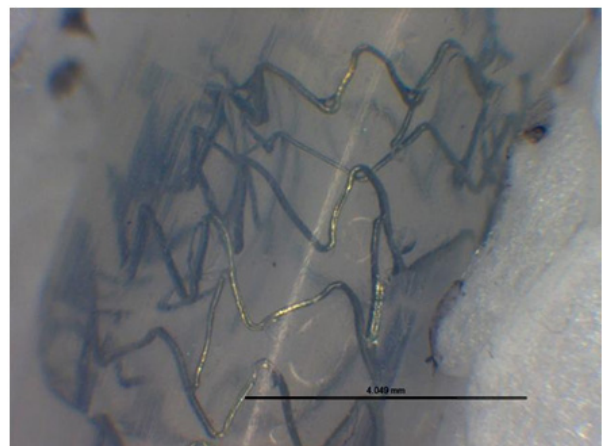

Figure 4: Stereomicroscopic pictures of the procedure: stent is crimpled and electrode is in the tube (a), balloon expanded stent (b), fixed electrode (c), stent after the extraction of the electrode (d).

\section{$4.5 / 24 \mathrm{~mm}$ stent}

The head of the electrode caught the stent which can cause injuries to the inner surface of the vessels. Fig. 2 demonstrates the damages to the stent after electrode extraction.
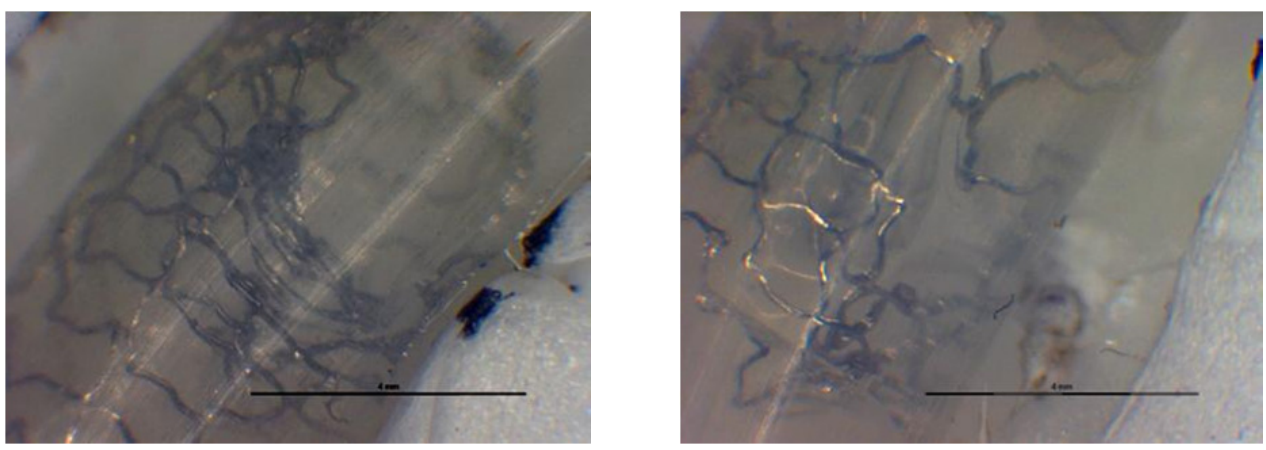

Figure 5: Liberté stent creased (left) and fractured (right) parts. 
$4.5 / 30 \mathrm{~mm}$ stent

In the picture below (Fig.6) it is seen clearly how the flanges stick up on the strut of the stent. The struts were deformed sorely.
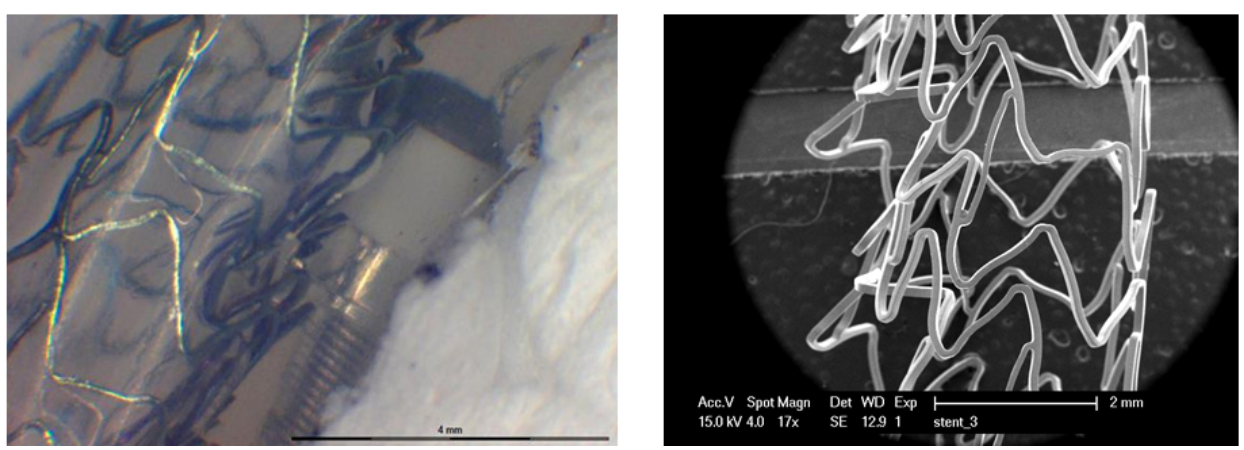

Figure 6: The head of the electrode during extraction (left) and the deformed stent after the procedure (right).

\section{$3.5 / 10 \mathrm{~mm}$ stent}

This is a drug eluting stent in a reservoir-base stent design. The stent became completely deformed and turned across in the tube which would involve grave consequences for human vessels during explantation. The reservoirs and slim parts of the struts may concentrate strain which may weaken the mechanical characteristics. Fig. 7 shows electron microscopic photographs of the damaged stent.
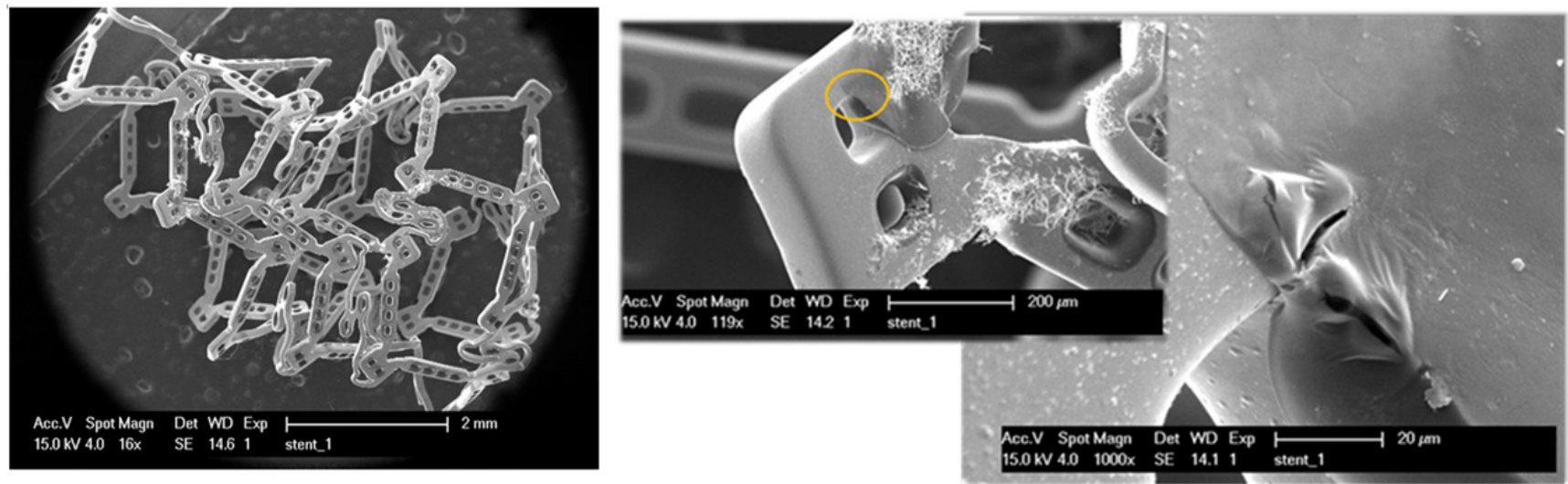

Figure 7: Deformed shape and damages to a reservoir stent.

\section{$3.5 / 10 \mathrm{~mm}$ stent}

The stent slipped out and was sheared as the electrode was removed. In the case of in vivo implantation, endothelisation occurs over time so a stent slipping out may cause internal injury.

Figs. 8 and 9 demonstrate the stent became deformed during electrode extraction.

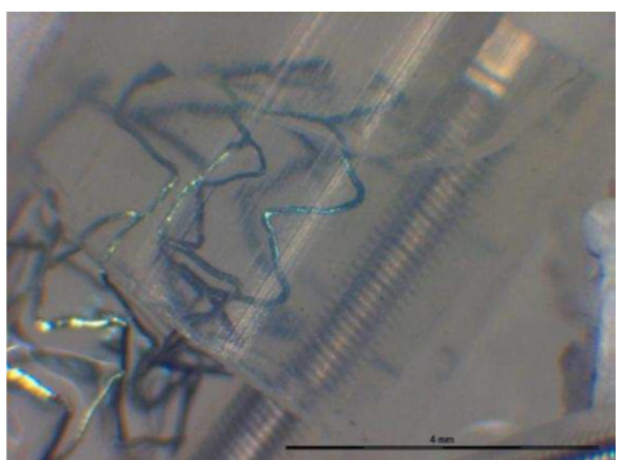

Figure 8: the beginning of electrode extraction

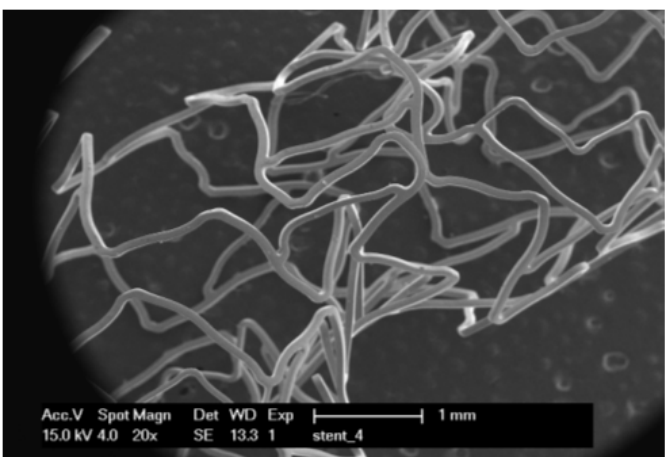

Figure 9: "S"-shaped stent after extraction 


\section{DAMAGES TO THE ELECTRODES}

he insulation of the electrode was damaged only once and not seriously. The scratch is not deep or long enough to prevent electric functioning (Fig. 10). However, the steroid ring was broken several times (Fig. 11). In the course of the experiments, the electrodes were in the tube only for a few minutes; implanted in vessels, they work for years and the steroid comes loose. This raises a question if an aged ring could lead to complications during explantation. To ensure greater security, another type of electrodes is recommended for use for stent implantation.

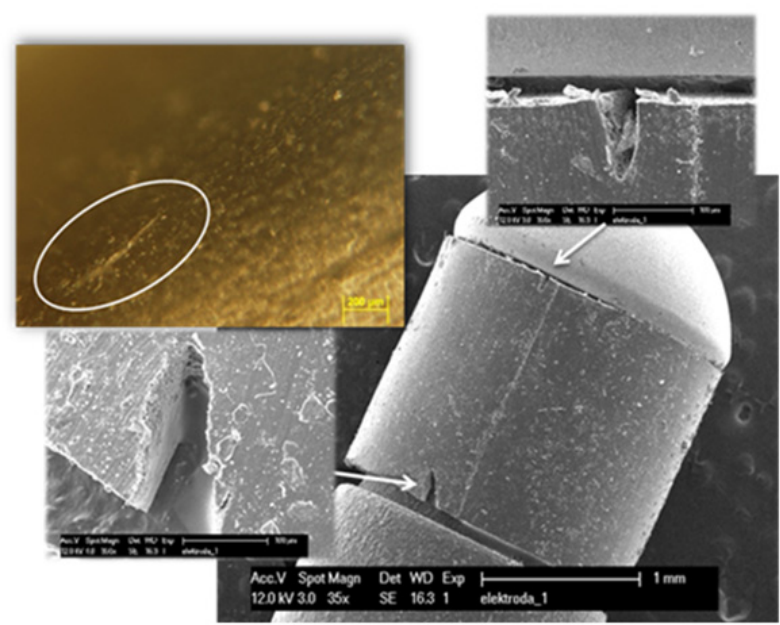

Figure 10: Damages to the electrode tip fixed with stent 2.
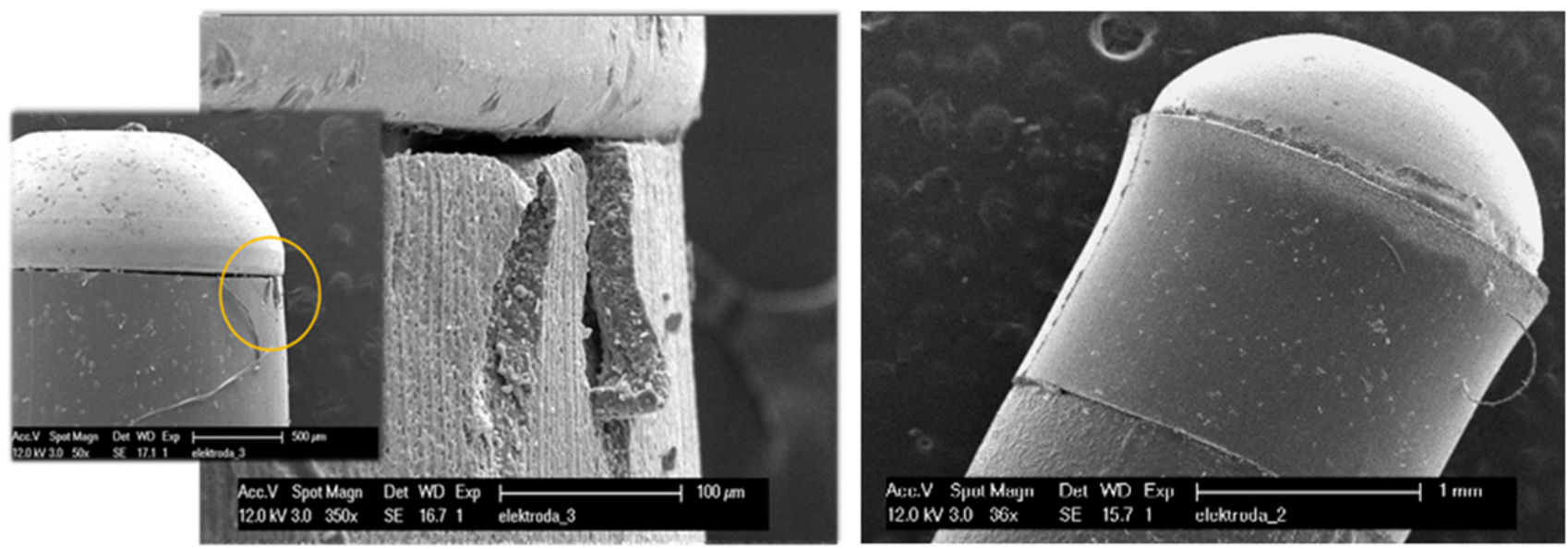

Figure 11: damaged steroid rings on electrodes fixed with stent 3 (left) and stent 4 (right).

\section{CONCLUSIONS}

$\mathrm{N}$ o damages were identified on the coating of the electrodes during microscopic examinations. The steroid ring peeled off from the tip of the electrode. It can cause complications only when the peeling is so substantial that the ring slips off and remains in the vessel during explantation. As regards design, stents with reservoirs may cause more problems during explantation. As regards length, shorter stents - 4. 3.5/10 mm and 5. 3.5/10 mm - are less suitable for fixation than longer ones. Stent implantation to stabilize the left ventricular lead with suitable stents is a useful and safe procedure in the treatment of CS lead instability. 


\section{REFERENCES}

[1] SS. Barold, RX. Stroobandt, AF. Sinnaeve, Cardiac Pacemakers Step By Step, Blackwell Publishing, ISBN: 1-40511647-1, (2004).

[2] Sz. Szilagyi, B. Merkely, E.Zima, A. Roka, G. Szücs, V. Kutyifa, A. Apor, L.Gellér In: Congress of The Hungarian Society Of Cardiology, Balatonfüred, Hungary, (2008).

[3] A. Achilli, F. Turreni, M. Gasparini, M. Lunati, M. Sassara, M. Santini, M. Landolina, L. Padeletti, A. Puglisi, M. Bocchiardo, S. Orazi, G. B. Perego, S. Valsecchi, A. Denaro, Efficacy of cardiac resynchronization therapy in very old patients: the Insync/Insync ICD Italian Registry, (2007).

[4] P. Szabadits, Zs. Puskás, J. Dobránszky, Acta of bioengineering and biomechanics, 11 (3) (2009) 11.

[5] CRT - Cardiac Resynchronization Therapy Implantation Procedure BIOTRONIK presentations. 